\title{
Estudantes do Prouni na crise do lulismo
}

\author{
Prouni scholars in the crisis of Lulism
}

\section{Henrique Bosso da Costa}

Resumo No ano de 2005, o governo Lula deu início ao Programa Universidade para Todos (Prouni), uma política pública criada com o propósito de formar mão de obra qualificada, abrindo espaço para que 1,4 milhão de pessoas de classes baixas chegassem ao ensino superior privado até 2014. Através do programa, o governo passou a dar isenções fiscais às instituições de ensino em troca da concessão de bolsas de estudo. Neste estudo de caso ampliado, utilizou-se a etnografia em uma grande universidade privada da cidade de São Paulo, em que jovens estudantes de cursos de tecnologia foram questionados sobre modos de vida, opiniões e expectativas sobre educação e trabalho, visões de mundo e da política em particular. Em busca de se manter em condições competitivas no mercado de trabalho contemporâneo, este grupo especialmente incorporado pela reestruturação produtiva vê no diploma uma "fuga para a frente", negando as características que marcaram o fordismo periférico da geração de seus pais. Palavras-chave Prouni. Lulismo. Etnografia. Reestruturação produtiva. Precariedade.

Abstract In 2005, the Lula government launched the University for All Program (Prouni), a public policy created to provide skilled labor, opening up space for 1.4 million people from lower classes to reach private higher education until 2014. Through the program, the government began to grant tax exemptions to educational institutions in exchange for the granting of scholarships. In this extended case study, ethnography was used in a large private university in the city of São Paulo, where young students of technology courses were questioned about lifestyles, opinions and expectations about education and work, worldviews and politics in particular. In order to maintain competitive conditions in the contemporary labor market, this group, especially incorporated by the productive restructuring, sees in the diploma an "fleeing forwards", denying the characteristics that marked the peripheral Fordism of the generation of their parents.

Keywords Prouni. Lulism. Etnography. Productive restructuring. Precariousness.

a Doutorando no Programa de pós-graduação em Ciências Sociais na Universidade Estadual de Campinas, mestre em Ciência Política pela Universidade de São Paulo e bacharel em Ciências Sociais pela mesma instituição. 


\section{INTRODUÇÃO}

Em 2014, cerca de 1,4 milhão de pessoas em todo o Brasil eram ou haviam sido atendidas por um dos programas de maior sucesso implementados pelos governos do Partido dos Trabalhadores (PT), o Programa Universidade para Todos (Prouni). Nesse mesmo ano, Dilma Rousseff foi reconduzida à Presidência do país, em um cenário diferente daquele que enfrentara quatro anos antes: as dificuldades econômicas que atingiriam o crescimento e o mercado de trabalho começavam a dar as caras, e com elas a crise política. No entanto, a petista foi reeleita com a vitalidade ainda imponente do lulismo, o pacto de governabilidade que, sob a liderança carismática do ex-presidente Luiz Inácio Lula da Silva e uma intensa valorização da demanda por produtos de exportação brasileiros, permitiu a opção política de execução de programas sociais e a inclusão de milhões de pessoas no mercado formal de trabalho e no mundo do consumo.

Na base paulistana do lulismo ${ }^{1}$, trabalhadores-estudantes se enfrentam em um mercado de trabalho reestruturado, no qual a manutenção de suas condições de empregabilidade depende de se manterem competitivos diante de uma concorrência sempre crescente. Para isso, buscam certificações que lhes garantam, via de regra, a simples manutenção no emprego e, eventualmente, alguma melhora como fruto da obstinação - embora, em muitos casos, não reste outra saída além da "viração" . Para formá-los, se oferece um sistema educacional privado, de baixa qualidade, responsável pela reprodução social por meio da reposição de uma mão de obra de remuneração igualmente baixa. Desse modo, políticas públicas focalizadas permitem que o Estado garanta simultaneamente a gestão da questão social, o fluxo contínuo de trabalhadores e o rendimento do capital pelo sistema de ensino privado.

Na periferia de São Paulo, era esse o cenário quando da eleição de Fernando Haddad para a prefeitura da capital, dois anos antes. O ex-ministro da Educação e criador do Prouni venceria a eleição mesmo com um baixo patamar inicial de

1 André Singer destaca que o primeiro aumento importante do salário mínimo ocorreu em maio de 2005, e"é razoável imaginar que a poderosa combinação Bolsa Família-salário mínimo tenha demorado alguns meses para produzir efeitos. Mas além do aumento obtido pelos milhões que recebem um salário mínimo da Previdência Social, outra possibilidade aberta aos aposentados, às vezes principal fonte de recursos em pequenas comunidades, foi o uso do crédito consignado" (SINGER, 2009, p. 93). Essa mistura de políticas públicas e renovação da base da pirâmide resultou na conversão desse setor antes hostil ao PT para a principal base eleitoral do partido.

2 Para Vera Telles, jovens que chegaram ao mercado de trabalho na década de 2000 "entraram em um mundo já revirado" (TELLES, 2006, p. 180), onde a precariedade e o desemprego banalizaram-se e as fronteiras entre o formal e o informal e entre o permanente e o temporário se diluem, mudando a forma como veem o trabalho: não mais pela busca de estabilidade, mas pela realidade dos empregos precários, de alta rotatividade e baixos salários. 
intenções de voto, contando com o impulso final do voto da periferia. Haddad, afinal, tinha o que mostrar: a gestão da nova questão social ${ }^{3}$ estivera no centro da atuação petista também nos governos que passou a comandar das prefeituras até a presidência. O caso que nos interessa, o Prouni, foi emblemático do momento de euforia vivido pelo país, quando mais da metade da população se tornou a "nova classe média" (como o governo petista, acompanhando a opinião de alguns economistas, passou a se referir a esse contingente) ${ }^{4}$ e teve acesso a políticas públicas variadas e de magnitude inédita. Além de incluir um vasto contingente de jovens das classes baixas no ensino superior privado e de garantir a retomada do crescimento do setor, o programa agregou-se a um conjunto de iniciativas de renovação do mercado de trabalho brasileiro e da demanda por um determinado tipo de mão de obra semiqualificada, porém de baixa remuneração. A realidade do pós-fordismo brasileiro acentuara sua contradição inerente: segundo Marcio Pochmann (2012), na década de 2000 foram criados 2,1 milhões de empregos por ano, mas 95\% deles pagavam até 1,5 salário mínimo.

$\mathrm{O}$ pano de fundo da reestruturação produtiva ajuda a compreender a fadiga que já começava a ser notada entre porções das periferias metropolitanas nos últimos anos, como demonstram as pesquisas de Gabriel Feltran em São Paulo. Essa percepção viria a se confirmar inclusive em antigos redutos petistas, como a região dos municípios de Santo André, São Bernardo do Campo e São Caetano, conhecida como ABC, e bairros paulistanos que foram os alicerces da formação do PT nas décadas de 1970 e 1980. O “projeto do trabalhador", que consolidou a perspectiva de luta dos movimentos populares nos anos 1980, vinha progressivamente dando espaço para a gestão do mercado da cidadania por organizações não governamentais (ONGs) e especialistas (FELTRAN, 2007). A flexibilização do trabalho e o neoliberalismo implodiam as pontes constituídas pela ideia de sociedade sala-

3 A questão social surge na lacuna entre a organização política e o sistema econômico como resultado da expansão do assalariamento. Esse espaço concerne ao "social": sistemas de regulações não mercantis, instituídas para tentar preencher esse espaço e promover integração. A sociedade salarial é, portanto, "também uma gestão política que associou a sociedade privada e a propriedade social, o desenvolvimento econômico e a conquista dos direitos sociais, o mercado e o Estado" (CASTEL, 2015, p. 478-479). Com a reestruturação produtiva, a questão social se renova em termos distintos, pois a trajetória de integração pelo direito ao trabalho e pela extensão das proteções sociais é interrompida, sendo substituídas pelas políticas de inserção, em que se "definem com precisão a clientela e as zonas singulares do espaço social" e se "desenvolvem estratégias específicas para elas" (CASTEL, 2015, p. 538). Para este artigo, será usado o termo inclusão para caracterizar esse fenômeno.

4 Segundo Marcelo Neri (2008), o grupo que ele denomina de classe C, ou "classe média” por critérios estritamente estatísticos, atingia 44,19\% da população em 2012, um crescimento de 17,03\% em seis anos. Apesar de considerar tais definições insuficientes e inadequadas para este estudo, importa citá-las para entender o sentido da aplicação das políticas públicas no contexto do lulismo. 
rial e de direitos e, com eles, a noção de educação pública e universal - sendo o Prouni o coroamento de um longo processo de formação de força de trabalho pelo setor privado de educação (PRANDI, 1982).

Tais alterações tanto no regime de acumulação quanto na ideologia do período também viriam impactar a maneira como os jovens se comportam diante do mercado, de suas opções profissionais e de suas perspectivas futuras. Ainda mais dramaticamente, afetariam a própria construção do caráter desse grupo social. Junto das novas tecnologias e da era da informação, a indistinção entre tempo do trabalho e tempo de não trabalho, bem como uma transformação na estrutura institucional, estimulam o trabalho de curto prazo, por contrato e temporário, em que as empresas eliminam camadas de burocracia e de estabilidade, tornando-se mais planas e flexíveis (SENnETT, 2012). A aposta dos governos do PT na gestão do social e no acesso à cidadania por meio do consumo contribuiria para a diluição da identidade de uma parte considerável da classe trabalhadora.

A enorme expansão de vagas no ensino superior na última década com o Prouni e o Fundo de Financiamento Estudantil (Fies) espelha à sua maneira o processo verificado na França a partir dos anos 1980 com o programa "8o\% au bac"5, levado a cabo pelo governo Mitterrand. Stéphane Beaud e Michel Pialoux (2009) estudaram as consequências desse conjunto de transformações na nova sociabilidade produzida entre a classe operária francesa. Os sociólogos constataram que o principal resultado do programa foi a desvalorização dos cursos profissionalizantes de nível médio, justamente aqueles que estruturavam a identidade operária francesa até meados dos anos 1970, e a "fuga para a frente", isto é, a recusa e o deslocamento dessa massa de jovens da classe trabalhadora das profissões técnicas em direção a uma incerta disputa das profissões de nível superior. Me apoiando no trabalho realizado por Beaud e Pialoux, onde a política de massificação do ensino médio provocou um processo de "desoperariação" das classes baixas e de enfrentamento geracional com a identidade operária, tracei um paralelo com o caso francês identificando no Prouni um instrumento de fuga das ocupações precárias e manuais.

Esses processos de subjetivação levariam a escolhas políticas que, até certo ponto, não haviam sido previstas. Em geral, os estudantes que acessam o Prouni são recém-saídos do ensino médio ${ }^{6}$. Embora a maioria já tenha trabalhado, neles

5 Referência ao baccalauréat, o diploma de ensino médio no sistema de ensino francês.

6 A seleção do Prouni é feita por meio do Exame Nacional do Ensino Médio (Enem). O programa exige que o aluno tenha cursado o ensino médio em escola pública ou com bolsa integral em escola privada. As bolsas integrais do programa são reservadas a estudantes com renda familiar per capita de até 1,5 salário mínimo, enquanto as parciais (50\%) são destinadas àqueles com renda familiar per capita de até 3 salários mínimos. Também oferece bolsas para os estudantes que 
percebemos uma adaptabilidade maior das condições do mercado de trabalho na área em que atuam, assim como uma incômoda resignação quanto a ele. Tendo sua relação com o tempo transformada pela flexibilização das relações de trabalho, é plausível apontar que todas as dimensões de suas vidas seriam igualmente afetadas pela impossibilidade de construir afinidades duradouras. Entre esses estudantes surgem aspectos de negação da condição trabalhadora e de incorporação do individualismo como perspectiva única.

No sentido de estruturar a reflexão, a pesquisa teve por objetivo mapear ideologicamente dois grupos de estudantes bolsistas do Prouni de uma grande universidade privada de massas, localizá-los no vasto universo do trabalho precário e em suas dimensões políticas possíveis. Na etnografia, selecionei 14 estudantes favorecidos pelo Prouni nas unidades Barra Funda, Vergueiro e Santo Amaro da Universidade $\mathrm{A}^{7}$, com os quais realizei, entre 2013 e 2014, ao menos duas entrevistas aprofundadas sobre questões que envolvem modos de vida, opiniões e expectativas sobre educação e trabalho, visões de mundo e da política em particular, além de ter visitado mais de duas dezenas de vezes os campi, onde estive por extensos períodos em meio aos alunos da instituição. Neste artigo, destaco um grupo de trabalhadores-estudantes de um setor dinâmico do capitalismo pós-fordista, o de serviços em empresas de tecnologia, call centers, comércio, marketing eletrônico e segurança da informação. A última fase das entrevistas coincidiu, propositadamente, com o período da campanha presidencial de $2014^{8}$.

Como observam Gianpaolo Baiocchi e Brian T. Connor (2008), o olhar etnográfico volta-se para o estudo da política, ao defini-la como os eventos, instituições e atores que são normalmente consideradas "políticos”, mas em pequena escala; para o estudo dos encontros rotineiros entre as pessoas e aquelas instituições e atores normalmente invisíveis em abordagens não etnográficas; e para o estudo de outros tipos de eventos, instituições e atores de alguma forma consequentes para a política (como a apatia ou a não participação em movimentos sociais).

se autodeclaram pretos, pardos ou índios no ato da inscrição (obedecendo a um cálculo baseado no número de cidadãos pretos, pardos e indígenas em cada Unidade da Federação, segundo o último Censo do IBGE).

7 O nome da universidade será resguardado, tendo em vista evitar quaisquer problemas legais.

8 O presente artigo origina-se na pesquisa de mestrado desenvolvida no âmbito do Programa de Pós-Graduação em Ciência Política da Universidade de São Paulo (USP). A pesquisa contou com um segundo grupo de estudantes prounistas do curso de Pedagogia da mesma universidade do campus de Santo Amaro. O objetivo era comparar os dois grupos, que se diferenciavam pelo perfil dos cursos, pela localização dos campi, pelas trajetórias de vida e pela média de idade (22,3 anos entre os tecnólogos e de 28,8 entre as pedagogas). Devido a impossibilidade de aprofundar a análise de ambos neste espaço, privilegiei o grupo de tecnólogos, que considero mais representativo das tendências do mercado de trabalho e do ethos contemporâneo. Ver Costa, 2015 . 
Este último foco do olhar etnográfico vincula-se de maneira especial à análise apresentada neste artigo, sendo chamada de experiência vivida da política (lived experience of the politics).

A proposta metodológica que se mostrou adequada à pesquisa de tipo qualitativo, à etnografia política e à expansão de seus resultados para um contexto mais amplo foi o estudo de caso ampliado. Para Michael Burawoy (2009), a ciência reflexiva tem por princípio o diálogo, virtual ou real, entre observador e participantes, o qual se insere em um segundo diálogo, entre processo local e forças externas; tais forças, por seu turno, podem ser compreendidas apenas mediante a expansão do diálogo da teoria consigo mesma. Segundo o autor, a objetividade não é mensurada por procedimentos que assegurem um mapeamento acurado do mundo, mas pelo aumento do conhecimento, ou seja, pela reconstrução imaginativa que acomode às anomalias. Assim, o método do estudo de caso ampliado aplica a ciência reflexiva à etnografia, no sentido de extrair o geral do particular a fim de mover do "micro" ao "macro" e de conectar o presente ao futuro.

\section{O TRABALHO INFORMACIONAL E O DIPLOMA EM QUESTÃO}

A juventude que flutuou, no período do auge lulista, para a "classe C" foi também o principal alvo das políticas de ampliação do acesso ao ensino superior, com especial destaque para o Prouni. A associação entre mobilidade social e acesso ao ensino superior sugere, portanto, algumas questões importantes. Para Marcio Pochmann, a emergência econômica de grandes parcelas da população demonstraria um tipo de mobilidade dentro da própria classe trabalhadora, a partir da "recuperação recente da participação do rendimento do trabalho na renda nacional" (Pochmann, 2012, p. 19), o que significa ampliação da taxa de ocupação e da formalização dos empregos, além de queda da pobreza absoluta. Essa renovação na base da pirâmide social brasileira seria puxada, sobretudo, pelo setor terciário, o qual gerou 2,3 vezes mais empregos do que o setor secundário.

Concomitantemente à mobilidade, houve um incremento da formação escolar na base da pirâmide. Os dados da Relação Anual de Informações Sociais (Rais), publicada pelo Ministério do Trabalho e Emprego (MTE), mostram a manutenção da trajetória de elevação do nível de instrução formal dos trabalhadores, com ligeiro aumento da participação dos vínculos formais de empregos ocupados por trabalhadores com ensino médio completo, que alcançou 45,2\%, e com ensino superior completo, que correspondeu a 18,5\%. Ao mesmo tempo, caiu a participação dos vínculos de trabalhadores com até o ensino fundamental incompleto, passando de 25,8\%, em 2012, para 24,5\%, em 2013 (DiEese, 2014). 
Com base na Pesquisa Nacional por Amostra de Domicílio (PNAD), Álvaro Comin e Rogério Barbosa (2011, p. 77) analisaram a variação da média de anos de estudo entre 1995 e 2009, notando que se alterou significativamente a distribuição dos indivíduos quanto aos graus completos, reduzindo-se a quantidade de pessoas sem níveis de ensino completos, com um crescimento acelerado da participação relativa dos níveis de ensino mais elevados. Em relação ao conjunto de indivíduos no ensino superior, os dados apontavam que o crescimento das vagas atingia principalmente a população ocupada, sobretudo aquela com uma jornada superior a 40 horas semanais. O perfil etário desses estudantes sugere que se trata, na maioria, de pessoas já há muito inseridas no mercado de trabalho, as quais retornam aos estudos em proporção cada vez maior. A tendência de envelhecimento da população no ensino superior é nítida: em 1995, 31\% dos estudantes de graduação brasileiros tinham mais de 25 anos, enquanto em 2009 esse número alcançava $40 \%$.

$\mathrm{O}$ trabalho informacional, no qual se inserem os estudantes de Tecnologia entrevistados, é atravessado por essas transformações recentes no mercado de trabalho brasileiro, atraindo a atenção de jovens dispostos a seguir carreiras diferentes daquelas praticadas por seus pais - operários, servidores públicos, professores e empregadas domésticas são algumas das ocupações parentais mencionadas pelos entrevistados.

Para compreender esse processo, pode ser útil fazer uma aproximação comparativa entre os casos brasileiro e francês. Alguns autores permitem observar que, embora com formações de classe e desenvolvimentos históricos específicos, eles apresentam similaridades a partir da substituição do modelo fordista pela introdução de formas flexíveis de acumulação que afetam as relações de produção em nível global e em sua versão periférica (BRAGA, 2003, p. 34). Robert Castel (2015), Braga (2003), entre outros, veem a precarização do trabalho como um processo central, comandado pelas novas exigências tecnológicas e econômicas do capitalismo moderno, tanto aqui como na França, e não como um processo genérico de "exclusão" social.

Segundo Isabel Georges (2009), as vagas de emprego no setor informacional - ela utiliza o exemplo do telemarketing, a mais precária das profissões da área exigem nível de escolaridade relativamente elevado, sendo este um dos principais critérios de seleção no momento do recrutamento. Por outro lado, o "rendimento" dessa escolaridade é muito baixo, geralmente colocando o trabalhador em uma situação de sobrequalificação no que concerne a sua ocupação. Tal situação pode favorecer a emergência de uma "relação paradoxal em relação à escola", pois esta não favorece o acesso ao emprego qualificado, mas a ocupações que, como nesse 
caso, desvalorizam os saberes adquiridos (GEORGEs, 2009, p. 227). A conclusão da autora sugere que somente aqueles que contam com certa estabilidade socioprofissional dos pais e começam os estudos superiores tendo frequentado o ensino médio em estabelecimentos privados ou escolas profissionalizantes públicas têm pretensões de mobilidade.

A "fuga para a frente" é um dos motivos para que a desintegração do mercado de trabalho atinja com tanta dramaticidade o jovem trabalhador precário. Ela se dá diante da pressão extenuante por qualificação que vem diretamente das empresas contratantes. Como alertava Robert Castel, ao elevar o nível das qualificações exigidas, elas criam uma situação na qual jovens que "há vinte anos teriam sido integrados sem problemas à produção acham-se condenados a vagar de estágio em estágio ou de um pequeno serviço a outro" (CASTEL, 2015, p. 538). O primeiro resultado desse novo quadro é que jovens sem qualificação ficam sem alternativas ao desemprego, pois os postos que poderiam ocupar já estão tomados por aqueles que detêm um certificado superior. Além disso, e de maneira mais profunda, faz com que políticas públicas de qualificação profissional como o Prouni pareçam inválidas como alternativas para evitar o desemprego ou precaver contra a "não empregabilidade": o mais provável é que essas políticas resultem no aumento do número de desempregados qualificados.

Para esses jovens, a preocupação prioritária reside em se manter em condições competitivas no mercado de trabalho que, por causa da grande oferta de mão de obra, seleciona cada vez mais pelo critério do diploma. No período em que realizei as entrevistas, Rodolfo ${ }^{9}, 22$ anos, era estudante de Segurança da Informação no campus Vergueiro da Universidade A. Em uma noite de outubro de 2014, ele me recebeu na entrada da faculdade, portando sobretudo e um ar soturno. Entre seus pares entrevistados, ele é o que se encontra mais próximo da classe média. Seu primeiro emprego foi em 2009, como estoquista em uma loja de roupas, onde ficou por cerca de sete meses. Na época, ele cursava o ensino médio e trabalhava, quando começou a fazer um curso técnico de informática em uma Escola Técnica Estadual (Etec), junto do ensino secundário, e deixou o emprego. Quando ele nasceu, seus pais e as duas irmãs mais velhas se mudaram para a Vila Mariana, atualmente um bairro de classe média na Zona Sul de São Paulo. O pai começou sua vida profissional como auxiliar de cozinha em padarias, quando chegou à cidade, e conseguiu progredir até se tornar cozinheiro profissional - uma trajetória difícil de se reproduzir nos dias de hoje.

9 Os nomes dos entrevistados foram substituídos por nomes fictícios, para preservar sua identidade. 
A despeito da inflação que atingiu o valor dos imóveis na capital nos anos 2000 (e principalmente em bairros próximos ao centro, como a Vila Mariana), Rodolfo justifica a melhora das condições de vida pelo fato de ele e suas irmãs terem começado a trabalhar cedo e porque o aluguel é antigo e os donos do imóvel são amigos da família. Diz que sem o Prouni não teria como fazer faculdade e, desempregado, não poderia arcar com a despesa. Ele começou a se interessar por informática ainda durante o ensino médio, frequentando um telecentro da Prefeitura de São Paulo, implementado pela gestão petista de Marta Suplicy, quando teve a primeira oportunidade de acessar a internet. Rodolfo admite que a situação da família melhorou nas últimas décadas, apesar de atribuir a relativa estabilidade econômica atual, como é recorrente nas entrevistas que fiz, ao trabalho e à perseverança da família.

É porque a classe média... é engraçado eu dizer. Eu tinha um amigo que era de classe média. Ele morava ali perto da Vila Mariana, tinha um excelente apartamento, grande, eles eram uma família... a gente brincava, você é maior "ricão", mas eles eram de classe média. Mas teve um contratempo, e por um deslize hoje eles são de classe baixa. Para haver um deslize e você cair ou subir, não é porque você está no meio, é porque estava em um patamar e desceu pra outro. "Ah, aconteceu um acidente, agora sou da classe baixa e daqui uns dias eu volto pra classe média, daqui uns dias eu sou da...” Eu diria assim: se é tão flexível que você mude de classe, então não existe essa do meio. Ou você é uma ou você não é. Então se você é quase rico, você é pobre; se você é quase pobre, você é rico. (Rodolfo, 22 anos)

O contexto de desigualdades regionais no tecido urbano de São Paulo também influencia a percepção dos estudantes diante dos obstáculos colocados pela inserção no mercado de trabalho. Em outra região da cidade, jovens que veem no trabalho informacional uma saída para um eventual destino operário miram um estilo de vida diferente, semelhante ao da classe média tradicional. Apesar de reconhecer o Itaim Paulista como uma região carente, Fernanda, aluna do curso de Tecnologia em Sistemas para Internet no campus Barra Funda da Universidade A, não leva esse aspecto em consideração quando compara seu bairro à Zona Sul paulistana, que ela considera mais desenvolvida. Filha de pais nordestinos divorciados, ela, com 24 anos, separada e mãe de uma filha, costuma sair do bairro no extremo da Zona Leste para se divertir na Zona Sul. 
O que você identifica de tão diferente assim entre as zonas Leste e Sul? $\mathrm{Na}$ Zona Leste, eu não gosto muito dos bares de lá. Não gosto. A estrutura dos lugares, a educação das pessoas... é tudo diferente, os hábitos. A gente está na mesma cidade, mas de uma zona para outra é completamente diferente.

Por que você acha que é assim?

Não sei te dizer. Não posso dizer que é a condição financeira, porque isso não influencia a pessoa, é algo que vem da cultura dela. Mas, na Zona Leste, eu acho muito bagunçado. Eu não me identifico com a Zona Leste. (Fernanda, 24 anos)

Quando conversamos pela primeira vez, em 2013, Fernanda procurava estágio na área de Tecnologia - ela diz não ter se identificado com o último emprego, como escriturária na área de previdência privada do Banco do Brasil, de onde havia saído cerca de dois meses antes da entrevista. Para isso encarou o ciúme do ex-marido, que não a deixava estudar, prestou o Enem e mirou na área de Tecnologia da Informação (TI). Mas, assim como outros entrevistados, escolheu o curso pela facilidade de acesso - ela gosta mais de banco de dados, "que é a parte que está por trás do que você vê" na internet, explica.

Na medida em que o modo de regulação $0^{10}$ contemporâneo é também uma forma de negação da questão social como questão política, erigindo em seu lugar técnicas focalizadas e imediatas de gerenciamento da desigualdade, como se comportariam então jovens nessas condições de vida diante do lulismo? Seria razoável afirmar que esse "público-alvo" se comportasse como tal, visto que o Prouni, para eles, é exatamente uma política de gerenciamento de uma população "pendurada por um fio”, como diria Robert Castel (2015)?

O esvaziamento do Estado de sua dimensão propriamente política não é uma invenção petista, mas encontrou no partido um executor competente. Na posição de gestor da questão social no Ministério da Educação, Fernando Haddad implementou o Prouni a partir de pressupostos assumidamente técnicos de eficiência, levando à prática o ensinamento de Herbert Marcuse de que "racional é aquele que mais eficientemente aceita e executa o que lhe é determinado, que confia seu destino às grandes empresas e organizações que administram o aparato” (MARCuSE,

10 Leda Paulani (2009, p. 26) define o modo de regulação como "as instituições, normas, os modos de cálculo e procedimentos que asseguram a reprodução do capital como relação social”. Trata-se de um conjunto de cinco formas institucionais - a relação de trabalho, a relação concorrencial intercapitalista, o regime monetário e financeiro, a forma de organização do Estado e o regime internacional - que quando combinadas determinam a forma específica que assume a acumulação de capital em cada momento histórico. 
1999, p. 97). À época da tramitação do Projeto de Lei n. ${ }^{\circ} 3 \cdot 582 / 04$, que tratava da instituição do Prouni, Haddad e João Paulo Bachur (2004) afirmavam que o programa "foi idealizado justamente a partir do diagnóstico de que o setor privado de educação superior, apesar de movimentar quase 1\% do PIB nacional, não só não recolhia impostos como gerava uma contrapartida social ínfima” (HADDAD; BACHUR, 2004, p. 2). A maneira escolhida para lidar com a nova questão social teria como impacto a reprodução pelos seus beneficiários de um comportamento gerencial, de si mesmos e das escolhas ideológicas por ela estimuladas.

Um exemplo disso é a própria opinião dos entrevistados sobre o Prouni, segundo a qual a construção ideológica que envolve o projeto do trabalhador e a universalização de direitos é praticamente inexistente, dando lugar a uma visão pragmática da necessidade do diploma universitário e das exigências do mercado de trabalho. Nas falas dos entrevistados, o Prouni se revela como um programa apropriado aos tempos atuais: não pretende, na visão deles, construir cidadania ou mesmo carreiras de longo prazo, mas é um passo fundamental para "esquentar" o currículo e se manter no mercado de trabalho em condições de concorrer com outros milhares de jovens em situação similar. É o caso de Lúcia, que na época das entrevistas tinha 22 anos e era estudante do curso de Tecnologia em Banco de Dados, no campus Barra Funda da Universidade A. Para ela, o Prouni é uma ótima iniciativa, mas, ao mesmo tempo, Lúcia acha que "eles não estão fazendo muito mais que a obrigação". Cabe a instituições como a Universidade A abastecer o mercado de trabalho com mão de obra rapidamente disponível.

Não é incomum que os estudantes da área de Tecnologia se importem pouco com a escolha do curso, que os levaria a ocupações muito semelhantes. A maioria dos entrevistados escolheu o curso depois de ingressar no mercado de trabalho. O curso escolhido por Lúcia é resultado de convicção em falta e senso prático em demasia. Ela diz que se inscreveu para o Enem em três oportunidades, mas compareceu apenas na última tentativa. Depois do resultado, saiu em busca de faculdades:

Fui olhando pela nota de corte, porque é mais fácil você ver pela nota de corte do que pelo curso que você quer fazer. Então fui olhando pela nota de corte, fazendo uma seleção do que tornaria mais fácil pegar uma bolsa, então me inscrevi para os dois cursos que eles solicitam, e consegui os dois. (Lúcia, 22 anos) $)^{11}$

11 O período de inscrições para o Prouni dura uma semana, durante a qual o candidato tem acesso à nota de corte das instituições que lhe interessam, podendo então compará-la com a nota que obteve no Enem. 
São as dificuldades de uma vida de oportunidades limitadas que os levam a soluções imediatistas. Todos os estudantes do grupo pesquisado trabalhavam e ajudaram com a renda familiar em algum momento da vida. A bolsa do Prouni contribuiu para que alguns permanecessem no curso, eventualmente reduzindo a carga horária de trabalho ou a necessidade de um emprego mais estafante. Habitante da Vila Ré, no distrito da Penha, Lúcia morava próximo dos pais - o pai é funileiro e a mãe ela não soube precisar, ambos com o ensino fundamental completo. Em nossa primeira entrevista, realizada em outubro de 2013, Lúcia trabalhava como estagiária em uma empresa de treinamento e consultoria de software, no centro de São Paulo, ganhando um salário mínimo. Perguntada se notava uma diferença na oferta de emprego no centro da capital, respondeu que "sim, mas isso é óbvio. Eu acho que nunca vai ter um monte de empresa na Zona Leste suficiente para dar emprego para tanta gente que tem lá." Ela se queixava bastante da escola em que estudou no ensino médio. "Tudo ruim”, diz, referindo-se tanto à estrutura da escola quanto aos professores.

Lúcia conta que "muitas das coisas de Tecnologia que eu sei hoje aprendi sozinha, que a faculdade também não está ensinando muita coisa" - uma opinião compartilhada por outros entrevistados. Antes, ela havia feito o mesmo curso na unidade da Vila Maria, que achava melhor, "porque os professores eram mais dedicados", provavelmente pelo fato de que as salas tinham poucos alunos. "Não é como agora que é lotada a sala, que a gente teve até que trocar porque não tinha espaço”. A descrição de Lúcia ilustra o outro lado da moeda da utopia do trabalho informacional: um ano depois da primeira entrevista, Lúcia não trabalhava mais no mesmo emprego porque seu contrato de estágio havia se encerrado. Como vinha enfrentando dificuldade em encontrar outra ocupação na área, ela ajudava em um pet shop de uma amiga, "só pra quebrar o galho, porque cada dia parece que está mais difícil encontrar emprego na minha área”.

Juliana, estudante do curso de Sistemas da Informação no campus Vergueiro, tem 19 anos e opiniões agudas sobre o presente. Ela acha que seus colegas na Universidade A não se esforçam muito, e pensa o mesmo sobre seus amigos do bairro do Jabaquara, na Zona Sul, alguns deles moradores de uma favela nas proximidades de seu condomínio. Para ela, "ninguém mais pega na sua mão e diz que tem que fazer porque é importante", afirma em relação ao ensino atual, de modo que "você faz se você quiser" e quem não se esforça não consegue continuar. A jovem trabalhava à época em uma empresa de cobrança no centro da capital, como auxiliar de suporte técnico, com carteira de trabalho assinada e salário de $\mathrm{R} \$$ 900,00. Ela conta do orgulho de seus pais em ver o irmão (também aluno da 
Universidade A) e ela no ensino superior, que eles não tiveram oportunidade de cursar - sentimento recorrente entre os pais dos entrevistados, o que se explica em parte pela relação estudada por Beaud e Pialoux (2009) de uma geração passada com as próprias referências e a sofrida constatação de que nada têm a ensinar a seus filhos, trabalhadores precários cuja experiência e destino profissionais muito diferem dos seus.

Mas Juliana tem uma opinião pesadamente realista sobre o diploma universitário. Para ela, o certificado de conclusão é "aquela coisa escrita”, "burocrática”, "para colocar no currículo" e que importa mais porque as empresas exigem. Não que ela não considere necessário adquirir conhecimento, porém "não é só o diploma que faz uma pessoa, mas sim o esforço". Além do mais, “o conhecimento está na nossa cara" diz, referindo-se à internet.

Para mim, o diploma não é fundamental. Eu, infelizmente, estou fazendo só para ter no meu currículo. É claro que busco o conhecimento também, mas hoje as empresas só querem ver o que está escrito no seu currículo. Na verdade, acho que o objetivo de todo mundo é esse mesmo. (Juliana, 19 anos)

Naturalmente, quando perguntados sobre o futuro, os estudantes de tecnologia tentam demonstrar otimismo, na medida em que depositam no diploma universitário a esperança de se manterem em boas condições de competir no mercado de trabalho, incorrendo na repetição da afirmação de valores em que se veem aprisionados. Anderson tem 19 anos, estuda Ciências da Computação no campus Barra Funda da Universidade A, mora com a mãe no Brás e sustenta a casa com o novo salário, de 1,5 salário mínimo - até dois anos antes, ele trabalhava como programador $^{12}$ em uma empresa de desenvolvimento de websites no município de São Caetano do Sul, primeiro como estagiário e depois efetivado. Seus pais são separados: ela é manicure e ele, professor de História na rede pública. Anderson havia sido registrado na empresa poucas semanas antes de nossa primeira entrevista. Ele deposita confiança no futuro, mas sabe que a formação que está adquirindo na Universidade A assenta mais no âmbito da exigência do mercado do que necessariamente em um diferencial qualitativo.

12 A carreira de programador recebeu tratamento privilegiado pelos estudos do pós-fordismo informacional, a partir do conhecido estudo de Manuel Castells (2016). Contudo, para Braga (2009), tomando como base os trabalhadores das Centrais de Teleatividades (CTAs), ao contrário da promessa de emancipação presente na utopia da sociedade da informação, é mínima a possibilidade de que um jovem formado em uma universidade privada brasileira de massa venha a se integrar a ela. 
Eu acho que vai abrir bastante coisa, vai abrir bastante oportunidade, porque na minha área é necessária uma faculdade, 80\% das vagas são pra pessoal formado, então, se você não se forma, não tem como arrumar uma vaga, por menor que seja a vaga. Então acho que vai abrir algumas portas, algumas oportunidades boas. (Anderson, 19 anos)

O otimismo de Anderson contrasta com a pouca materialidade que ele é capaz de colocar em seus projetos futuros. Ele sabe que a formação que a faculdade lhe proporciona serve apenas como uma garantia mínima: a de não ser eliminado nessa primeira barreira do mercado de trabalho. O otimismo serve como um valor ético, atemporal, que, ao contrário de negar o extremo realismo que ele e os demais cultivam, paralisa-os naquela condição de curto prazo. Como diz Sennett, Anderson "tornou-se estático; está encurralado na pura e simples afirmação de valores" (SEnNet, 2012, p. 31).

A situação não é diferente para Jéssica, que frequentou por um ano o curso de Tecnologia de Sistemas para Internet, no campus Barra Funda da Universidade A. Ela tinha uma bolsa integral do Prouni, mas não gostou do curso, que imaginava ser semelhante a Publicidade ou Marketing, quando, na verdade, trata-se de um curso voltado para a área de Tecnologia. Com 24 anos, filha de um policial militar aposentado e de uma funcionária de escola pública, mora no bairro Cachoeirinha, na Zona Norte da capital, já trabalhou como babá e teve uma experiência no telemarketing, que achou "um pouco ruim, porque você tem que lidar com pessoas que se acham na razão de estar certas, estando erradas". Por causa do estresse do trabalho, não permaneceu muito tempo na profissão. Jéssica é um caso exemplar de "viradora”, como chamou Vera Telles (2006): já trabalhou como babá, com transporte escolar, em uma gráfica e no telemarketing e, naquele momento, procurava emprego novamente.

O que você achava do trabalho no telemarketing?

É para quem quer ganhar dinheiro fácil e rápido. Porque essa empresa foi boa para ganhar dinheiro fácil e rápido, mas se você não tomar cuidado, acaba surtando lá dentro.

Por quê?

Porque é muito puxado, o funcionário é muito desvalorizado. Apesar de você ter a parte financeira boa, não compensa muito. Mexe muito com a estrutura 
psicológica da pessoa. O tempo que eu trabalhei lá... eu saí de lá por questões de saúde, porque já não estava mais aguentando, estava mexendo... mexe muito com o seu psicológico... dependendo da área que você trabalha, se é no SAC [Serviço de Atendimento ao Consumidor], se é cobrança, se é atendimento ao cliente, se é vendas... é meio puxado. (Jéssica, 24 anos)

Para esses jovens, o conjunto de circunstâncias que atravessam sua relação com o trabalho desagua num caráter moldado por esse tipo de significação limitada de planos e relações. A “fuga para a frente” é nada mais do que esse aprisionamento na afirmação de um otimismo de difícil realização, já que não se fundamenta em um projeto realista de futuro. Junto das novas tecnologias e da era da informação, vêm a implosão das distinções entre tempo do trabalho e tempo do não trabalho e a elevação exponencial do trabalho abstrato, uma transformação na estrutura institucional acompanhada do trabalho de curto prazo. É sua relação com o tempo que muda, tempo que o mercado de trabalho no capitalismo flexível não lhes oferece.

Nada que lembre, por outro lado, uma nostalgia de um fordismo idílico, impondo-se para eles uma realidade ainda mais deteriorada. Por sinal, a tarefa de decifrar seus valores já nasce com uma perspectiva diferente: para eles nunca houve degradação das condições do mercado de trabalho. Eles já sentiram esse mundo "pós-fordista" a pleno vapor, o que condicionou todas as suas experiências de vida para além do próprio trabalho.

\section{O CETICISMO EM RELAÇÃO À POLÍTICA}

Em tal contexto, esses jovens naturalmente responderiam a outros estímulos, muito diferentes daqueles que rondaram o imaginário das classes trabalhadoras as quais testemunharam o nascimento do PT e que vão diluindo as expectativas de conquista de direitos por meio do associativismo dos anos 1980 (FELTRAN, 2007). A política, para os jovens estudantes de Tecnologia que entrevistei, é não apenas algo distante de seu cotidiano, mas também indefinível em seus conceitos normativos básicos. Poucos souberam mobilizar posições de esquerda ou de direita, identificar coerentemente seus representantes e se associar a eles. Não se trata nem mesmo de uma influência indireta, mas de outra geração nascida para a política já com o PT no poder.

Com uma reiterada sensação de que não há grandes diferenças entre os partidos, restando o apego a personalidades que fujam do estereótipo, Ricardo, de 28 anos e morador de Ermelino Matarazzo, no extremo da Zona Leste da capital, dá um parecer curioso quando perguntado sobre os políticos que admira: 
Eduardo Suplicy, então senador pelo PT, Plínio de Arruda Sampaio, candidato a presidente pelo Partido Socialismo e Liberdade (PSOL) em 2010, e Éneas Carneiro, folclórico político da extrema-direita, candidato à Presidência por diversas vezes e que chegou a se eleger deputado federal. "Ele era muito inteligente", diz, "só que ninguém levava ele a sério”.

Ricardo, por ser o mais velho do grupo, teria, em tese, mais condições de avaliar diferenças entre os últimos governos. Ele era aluno de Sistemas da Informação no campus Barra Funda da Universidade A - o curso ensina a elaborar softwares que vão desde programas básicos de controle de estoque até sistemas de processamento de informações. Seu pai, gerente de uma loja de material de construção, e sua mãe, dona de casa, são separados, e ele sustentava a casa em que morava com a avó, trabalhando em tempo integral em uma empresa terceirizada, com salário de 1,5 salário mínimo, em Guarulhos. Perguntado se tem lembranças do governo de Fernando Henrique Cardoso, Ricardo diz que não vê diferenças entre os governos do Partido da Social Democracia Brasileira (PSDB) e petista. Inclusive, via repetir com Dilma a mesma política de privatizações. "Pra mim, a maior jogada do Fernando Henrique foi o [Plano] Real, que estabilizou um pouco o país, sei lá. Mas falar que os caras fizeram algo além de vender todas as nossas estatais... não vi diferença nenhuma. E a Dilma fazendo a mesma coisa, um partido dizia-se de esquerda, agora fazendo a mesma que todos os outros fizeram.”

Com exceção de Anderson, de 19 anos, nenhum dos estudantes de Tecnologia demonstrava afinidade com o PT. A mãe de Anderson não gosta do partido, mas seu pai, com quem diz não ter muito contato (eles são divorciados), é simpatizante. Ele tem votado no PT nas últimas eleições, mas não admite que isso se dê por influência do pai, professor de História da rede estadual e "que vai votar de camisa vermelha e tudo mais". Diz que começou a notar a política com as manifestações de junho de 2013 e achou que, naquele momento, precisava tomar um lado. "Fui na internet, comecei a procurar, li uns artigos, não lembro de quem agora, mas li uns artigos. E comecei a me informar um pouco". As declarações de Anderson sugerem uma relação idealizada com o pai, a única conexão com o PT que existe em seu relato. A família da mãe, com quem tem mais contato, é refratária ao partido e tem votado na oposição. Na relação com eles, Anderson diz ser "do contra".

Anne Müxel (1997, p. 153) comenta em investigação sobre a juventude francesa dos anos 1990, que nessa década a palavra "política” suscitava rejeição e imagens negativas, trazendo a crise de representação para a superfície. Em sua pesquisa, a socióloga francesa coletou denúncias de promessas não cumpridas pela esquerda francesa e o desencanto gerado por isso, levando a uma falência da própria ideia 
de projeto político. A retórica do desencanto, por sua vez, acabava servindo para alimentar a suspeita de mentira que recai sobre a política e para legitimar um relacionamento desiludido e distanciado da juventude em relação a esta.

Para identificar esse processo, a autora recolheu depoimentos de jovens, na França, que haviam iniciado sua participação na política institucional durante o governo socialista de François Mitterrand, exatamente o responsável pelo "fim das ilusões", nas palavras de seus entrevistados. Como também vimos em Beaud e Pialoux (2009), a passagem do Partido Socialista pelo governo francês foi um marco na desconstrução da identidade operária, partindo exatamente do novo paradigma educacional oferecido para os jovens da classe trabalhadora. Com base nesse exemplo, é possível interpretar as entrevistas com os jovens brasileiros do século XXI sob a mesma lente. Isso significa aceitar que estes "nasceram" para a política durante um governo do PT, finalmente quando a esquerda local chegava ao poder e estabelecia uma longa hegemonia. Exatamente porque não há para eles a experiência de outra agremiação que simbolizasse o poder, é compreensível que esses jovens na casa dos 20 anos não fizessem associação positiva com o partido que começava a colher o desgaste da longevidade.

A entrevista de Jéssica demonstra como os novos hábitos associados a essa geração, em especial o uso intenso das redes sociais, denotam uma nova relação com a política e potencializam o desconforto de alguns jovens desse estrato social com o PT. Ouvindo-a contar o caso de uma "informação" a que teve acesso por meio da rede social Facebook, deparei-me com uma mistura de ingenuidade e má vontade com Dilma Rousseff. Uma "notícia" ali compartilhada, das mais fajutas, não suscitou a desconfiança de Jéssica. Pelo contrário, serviu para legitimar sua posição.

Questão de política mesmo, eu não sabia da história da Dilma. Um professor meu publicou uma reportagem no Facebook e eu fui ler. Aí fiquei sabendo coisas da Dilma. Foi uma das partes que também me desagradou do PT. Que eu não sabia, por exemplo, que ela não podia pisar em vários países porque era procurada. Tem várias coisas de que eu não fazia ideia, então isso foi importante na minha opinião política. Interferiu bastante, porque como eu já não simpatizava muito [com a Dilma], não tinha muito o que me agradasse, mas também não tinha o que me desagradasse. Quando comecei a ler e fiquei sabendo um pouco mais, por esse meu professor, comecei a ter coisas contra. Antes eu não tinha nem a favor, nem contra, mas então passei a ter coisas contra. (Jéssica, 24 anos) 
Reunindo os vários elementos presentes em seus discursos, as entrevistas com os estudantes apontam para a afirmação de um caráter moldado pelo regime de trabalho flexível e pela perda de horizontes de longo prazo, consagrando o que Marcuse definiu como uma racionalidade da competição, "em que o interesse racional foi substituído pelo interesse de mercado, e a conquista individual foi absorvida pela eficiência” (MARcuse, 1999, p. 97). Visto como elitizado e de perfil "gestor" pela mídia tradicional e pelo eleitorado de classe média, o PSDB parecia ser a opção intuitiva naquele momento às reflexões desses jovens trabalhadores do que o datado projeto do trabalhador que o PT ainda diz representar. Fernanda é a entrevistada que ilustra com mais ênfase essa postura. Ela se declara abertamente antipetista, por isso votou em Marina Silva, no primeiro turno das eleições de 2014, e em Aécio Neves, no segundo. Um ano antes, Fernanda era mais comedida. Dizia que tinha "uma opinião sobre o PT", que era, na verdade, uma sentença: "eu não voto nesse partido". Ela já havia votado em José Serra na eleição presidencial de 2010. Assim como Jéssica, Fernanda instrumentaliza a imprensa para legitimar uma posição que é ideológica, porque, diz ela, “o PSDB pega em um nível mais alto”, uma clara referência à imagem elitista que muitos associam aos tucanos.

\section{Por que você não gosta do PT?}

É errado eu pensar dessa forma, mas eu não gosto de discutir sobre política. Pode me agregar, mas eu não tenho conhecimento para discutir sobre isso. Mas é uma opinião que eu tenho a respeito do PT, sobre muitas coisas, até mesmo que a gente vê na imprensa, então, naquela época, decidi por votar no Serra.

\section{Você acha que tem diferença entre o PT e o PSDB?}

Tem diferença, mas eu acredito que o PT tem que de alguma forma trazer seus eleitores, assim, um público mais carente. Eles pegam um ponto mais carente. E o PSDB já pega em um nível mais alto. Eu não entendo muito disso, por isso decidi... eu não tenho nenhuma opinião formada sobre nenhum dos partidos, por isso votei nulo nas últimas eleições [municipais] em São Paulo. Eu vou continuar assim.

\section{Sobre o governo Dilma, você tem alguma opinião?}

É um governo carente. A Dilma, eu acredito que está muito perdida no governo. Ela está sendo baseada, sustentada pelo Lula, eu acredito que seja isso. Mas é só essa opinião que eu tenho. Acredito que é um governo que não está sendo bom. E deixa muito a desejar. (Fernanda, 24 anos) 
Fernanda foca sua rejeição ao PT naquilo que é mais frequente na crítica das classes médias tradicionais ao partido: sua vinculação aos pobres e ao voto supostamente irrefletido manifestado por eles, uma acusação bastante semelhante à que se fazia ao populismo varguista e que tem sido frequente nas últimas eleições. Quando diz que o PSDB “pega em um nível mais alto”, a prounista moradora do Itaim Paulista, no extremo leste de São Paulo, faz referência ao eleitor geralmente associado aos tucanos, ou seja, o morador do centro expandido, de melhor renda e escolaridade. Em contraposição, o PT falaria “para baixo”, para os menos instruídos e carentes da capacidade cognitiva necessária para o exercício do voto. O discurso de Fernanda explicita não apenas essa visão manifestada por parte da classe média, mas como setores da população precarizada, sobretudo os mais jovens, estão dispostos a assimilar esse ideário quando alcançam melhores condições materiais de vida, mirando a ideologia do lugar aonde querem chegar. Por ironia, foi, no entanto, durante a década lulista que esse avanço material se efetivou.

Eles [os políticos] têm uma facilidade muito grande de enganar as pessoas. Sou muito pessimista em relação à política, acho que nunca vai melhorar, só se jogar uma bomba no Congresso Nacional. São coisas que a gente vai percebendo e é por isso que está essa merda. Eu falei com os meus pais e eles disseram que sempre teve muito lixo na política. Mesmo que um político tenha boa intenção no começo, depois que ele entra nesse meio... é muito poder, muito dinheiro envolvido, e ele acaba perdendo o foco da missão que tinha. (Juliana, 19 anos)

Jéssica e Juliana reforçam uma visão cética sobre a política e o senso comum de que a política corrompe, e os candidatos menos competitivos não teriam "competência”. Portanto, nenhum político serve e tudo vai continuar como está - por isso o voto nulo em todos os níveis na primeira rodada eleitoral. Quando Juliana ressalta que o PT está há 12 anos no governo, no entanto, a visão instrumental da política aponta diretamente para o partido que está no poder, sofrendo o desgaste da longevidade. Para essas jovens que votam pela primeira ou segunda vez, não há referências de virtudes ou escândalos políticos de outros partidos. Juliana diz também não gostar do governador de São Paulo, o tucano Geraldo Alckmin, mas não sabe identificar um motivo específico. De modo que a Presidência da República canaliza suas insatisfações, posição representada pela maioria dos estudantes 
entrevistados, que rejeitaram Dilma no primeiro turno ${ }^{13}$ e aderiram em minoria no segundo, e que acredita que dependa apenas de si mesma.

\section{CONSIDERAÇ̃̃ES FINAIS}

O Prouni é uma tecnologia de gestão social desenhada pelo governo Lula que, ao mesmo tempo, dá seguimento a um modelo de reprodução da força de trabalho semiqualificada e de baixa remuneração, de acordo com o que Francisco de Oliveira (2003) já havia identificado na diluição progressiva da diferença entre trabalho formal e informal, na alta rotatividade e na precarização das relações de trabalho. Seu sucesso em incluir centenas de milhares de jovens no ensino superior fez com que o programa tivesse continuidade na gestão Dilma, e mesmo após a cassação de seu mandato, em agosto de 2016. Enquanto o processo de impeachment da presidente se efetivava, o número de beneficiários do Prouni chegava, no segundo semestre daquele ano, a 1,9 milhão em todo o Brasil, segundo o Ministério da Educação (MEC) ${ }^{14}$, sendo esses estudantes uma parcela do eleitorado brasileiro que progrediu economicamente nos 13 anos de governo petista.

A crise econômica que se seguiu à reeleição de Dilma, e se aprofundou cada vez mais desde então - queda de 3,8\% no Produto Interno Bruto (PIB) de 2015, com recuo de $6,2 \%$ na indústria e $2,7 \%$ nos serviços (IBGE, 2015) -, bem como o processo institucional que culminou em sua cassação pareciam indicar o fim da hegemonia lulista iniciada em 2003. É possível enxergar sua força, entretanto, em um de seus programas sociais de maior sucesso: em 2017, já sob governo Temer, o MEC anunciou 214.110 bolsas do Prouni, entre integrais e parciais, o maior número já ofertado desde a criação do programa, e 5\% a mais em relação ao mesmo período do ano anterior, mesmo em contexto de queda na arrecadação federal ${ }^{15}$.

Na insatisfação desses jovens que representam uma categoria pouco notada nas discussões polarizadas dos últimos anos, emergem os sentimentos contraditórios que carregam esses trabalhadores-estudantes beneficiários do Prouni de que o país não lhes dá condições de competir no mercado de trabalho e fugir de empregos

13 No caso das estudantes de Pedagogia, classifiquei-as com base nas suas escolhas por vocação, nas expectativas de estabilidade, nas reflexões sobre desigualdade social e no projeto do trabalhador ainda presente de maneira residual. A hipótese de que esses elementos as amarrariam ao lulismo se confirmou com a sua adesão quase unânime (cinco das seis entrevistadas) a candidatura de Dilma já no primeiro turno de 2014 (CosTA, 2015).

14 Disponível em http://prouniportal.mec.gov.br/dados-e-estatisticas. Acesso em: 17 dez. 2019.

15 Folha De S. Paulo. "ProUni oferece mais de 214 mil bolsas, maior número desde a sua criação". Disponível em: http://www1.folha.uol.com.br/educacao/2017/01/1854462-prouni-oferece-mais-de-214-mil-bolsas-maior-numero-desde-a-sua-criacao.shtml. Acesso em: 23 de setembro de 2017. 
instáveis, mesmo com a posse de um diploma. Eles fazem parte de um regime econômico flexibilizado, em que tiveram sua relação com o tempo revirada pelos padrões impostos pelas empresas. Estão impedidos de planejar o futuro: "como se podem buscar objetivos de longo prazo? Como se podem manter relações sociais duráveis? Como pode um ser humano desenvolver uma narrativa de identidade e história de vida numa sociedade composta de episódios e fragmentos?" (SENNETT, 2012, p. 27). Em uma típica perspectiva weberiana, não estariam esses jovens simplesmente fazendo escolhas racionais diante das possibilidades escassas que lhes são dadas e que são comuns diante da sua situação de classe?

O quadro aqui descrito remete os jovens pesquisados imediatamente a uma relação superficial com a política. Esta, para fazer sentido, depende fundamentalmente de compromissos de longo prazo, precisamente o que o capitalismo hoje não permite, pela opressão cada vez maior do tempo. Era exatamente isso que diferenciava o fordismo, mesmo em sua versão periférica desenvolvimentista, possibilitando que o projeto do trabalhador pudesse avançar até a criação de instrumentos de luta política consolidados e ideologicamente consistentes, isto é, relações sociais duráveis. A reestruturação produtiva trouxe consigo uma nova relação com o tempo de trabalho e com o tempo da política, e uma nova forma de lidar com a questão social. Para que lado se inclinariam os prounistas paulistanos, em especial os jovens do estrato que identifiquei aqui, é umas das incógnitas fundamentais suscitadas pela crise do lulismo. O que era possível ver naquele momento é que, para jovens que veem a política pelos olhos do regime flexível e das políticas públicas focalizadas, buscar manter-se em condições mínimas de competição no mercado de trabalho é também reinterpretar a política pelo seu aspecto gerencial e descrer de seu sentido normativo.

\section{BIBLIOGRAFIA}

ABílıo, Ludmila Costhek. Dos traços da desigualdade ao desenho da gestão: trajetórias de vida e programas sociais na periferia de São Paulo. Dissertação (mestrado). Faculdade de Filosofia, Letras e Ciências Humanas da Universidade de São Paulo, São Paulo, 2005.

BAIOCCHI, Gianpaolo; Connor, Brian T. The ethnos in the polis: political etnography as a mode of inquiry. Sociology Compass, v. 2, n. 1, p. 139-155, 2008.

Beaud, Stéphane; Pialoux, Michel. Retorno à condição operária: investigação em fábricas da Peugeot na França. São Paulo: Boitempo, 2009. 
BRAGA, Ruy. “A vingança de Braverman: o infotaylorismo como contratempo”. In: ANTUNES, Ricardo; BRAGA, Ruy (orgs.). Infoproletários: degradação real do trabalho virtual. São Paulo: Boitempo, 2009, p. 59-88.

. A nostalgia do fordismo: modernização e crise na teoria da sociedade salarial. São Paulo: Xamã, 2003.

Burawoy, Michael. The extended case method: Four countries, four decades, four great transformations and one theoretical tradition. Berkeley: University of California Press, 2009.

CASTEL, Robert. As metamorfoses da questão social: uma crônica do salário. Petrópolis: Vozes, 2015.

Castells, Manuel. A sociedade em rede. Rio de Janeiro: Paz e Terra, 2016.

Comin, Álvaro A.; BARbosa, Rogério J. Trabalhar para estudar: sobre a pertinência da noção de transição escola-trabalho no Brasil. Novos Estudos, São Paulo, n. 91, p. 75-95, novembro de 2011.

Costa, Henrique. Entre o lulismo e o ceticismo: um estudo de caso com prounistas de São Paulo. Dissertação (mestrado). Faculdade de Filosofia, Letras e Ciências Humanas da Universidade de São Paulo, São Paulo, 2015.

DieEse. O Mercado de Trabalho Formal Brasileiro: resultados da RAIS 2013. São Paulo, setembro de 2014.

FELtRAn, Gabriel. Vinte anos depois: a construção democrática brasileira vista da periferia de São Paulo. Lua Nova, São Paulo, n. 72, p. 83-114, 2007.

Georges, Isabel. "Trajetórias profissionais e saberes escolares: o caso do telemarketing no Brasil”. In: Antunes, Ricardo; BRAGA, Ruy (orgs.). Infoproletários: degradação real do trabalho virtual. São Paulo: Boitempo, 2009, p. 213-230.

HADDAD, Fernando; BACHur, João Paulo. "Um passo atrás, dois à frente”. Folha de S. Paulo, São Paulo, 11 de dezembro de 2004, p. 2.

Iвge. Contas Nacionais Trimestrais. Indicadores de Volume e Valores Correntes: $4^{o}$ trimestre de 2015. Brasília, outubro/dezembro de 2015.

Marcuse, Herbert. Tecnologia, guerra e fascismo. São Paulo: Editora da UNESP, 1999.

Müxel, Anne. Jovens dos anos noventa: à procura de uma política sem 'rótulos'. Revista Brasileira de Educação, Rio de Janeiro, n. 5, p. 151-166, maio/junho/julho/agosto de 1997.

Neri, Marcelo Côrtes. A nova classe média. Rio de Janeiro: FGV/IBRE, CPS, 2008.

Oliveira, Francisco de. Crítica à razão dualista / O ornitorrinco. São Paulo: Boitempo, 2003.

PAULANI, Leda. A crise do regime de acumulação com dominância da valorização financeira e a situação do Brasil. Estudos Avançados, São Paulo, nº 23, 2009. 
Pochmann, Marcio. Nova classe média? O trabalho na base da pirâmide social brasileira. São Paulo: Boitempo, 2012.

PRANDI, José Reginaldo. Os favoritos degradados: ensino superior e profissões de nível universitário no Brasil hoje. São Paulo: Loyola, 1982.

SEnNETt, Richard. A corrosão do caráter: consequências pessoais do trabalho no novo capitalismo. Rio de Janeiro: Record, 2012.

TelLes, Vera da Silva. Mutações do trabalho e experiência urbana. Tempo Social, v. 18, n. 1, p. 173-195, junho de 2006. 